\title{
Curriculum, identidades y otras historias: una mirada de la historia de África y los afrodescendientes en el contexto bonaerense ${ }^{1}$
}

\author{
Francisco Ramallo² \\ UNMdP-CONICET, Argentina ${ }^{3}$ \\ franarg@hotmail.com
}

1 Artículo de reflexión.

2 Maestro en Estudios Étnicos y Africanos — UFBA—, Magíster, profesor y Licenciado en Historia UNMDP—, Especialista en Docencia Universitaria — UNMDP— y en Educación y TICS —ISFD N19—. Actualmente es becario de CONICET y doctorando en Humanidades y Artes con mención en Ciencias de la Educación —unR-

3 Docente e investigador del Departamento de Ciencias de la Educación de la Facultad de Humanidades — UNMDP—, miembro del Programa Interdisciplinario sobre Estudios Descoloniales PIED - y del Grupo de Investigadores en Educación y Estudios Culturales del Centro de Investigaciones Multidisciplinares en Educación — CIMED—. Su área de trabajo está vinculada a la historia de la educación, las perspectivas descoloniales y la didáctica de la historia. 


\title{
Curriculum, identidades y otras historias: una mirada de la historia de África y los afrodescendientes en el contexto bonaerense
}

\begin{abstract}
Resumen
En este artículo proponemos reflexionar sobre las razones por las cuales creemos que la historia de África y de los afrodescendientes cobra importancia, especialmente en la enseñanza de la historia en la escuela secundaria argentina. Nuestro abordaje está enmarcado en el análisis de las nuevas presencias y ausencias de estas culturas y pueblos en los diseños curriculares en el contexto de la Provincia de Buenos Aires, ya que en los últimos años se le prestó atención a la necesidad de revisar y renovar los contenidos escolares acordes con las demandas actuales de la sociedad. Allí estas otras historias se constituyeron como una novedosa aparición y ruptura en relación a las perspectivas y a los contenidos eurocentrados que caracterizaron la enseñanza de la historia mundial -ya no más denominada universal-. En la primera parte, luego de relatar nuestro recorrido de indagación, establecemos los principales aspectos que caracterizan a los diseños curriculares abordados; posteriormente, en la segunda parte, se establecen posibles líneas de trabajos que contribuyan a superar y revisar críticamente la Historia de Africa y de los afrodescendientes en estas normativas y en la construcción identitaria nacional.
\end{abstract}

Palabras claves: didáctica de la historia, África, afrodescendientes, perspectivas descoloniales, curriculum, identidad.

\section{Curriculum, identity(ies) and other stories: a look to the History of Africa and afro-descendants in Buenos Aires province context}

\begin{abstract}
This article proposes to reflect about the reasons by which we believe that the history of Africa and the afrodescendants becomes important, especially in the teaching of History in the Argentinian high school. Our approach is framed within the analysis of new presences and absences of these cultures and towns in the curricular designs in the context of the Buenos Aires Province, given that in the last years attention was payed to the need of reviewing and renovating the school contents according to the demands of the contemporary society. There this other histories constituted as a new appearance and rupture in relation with the Eurocentered perspectives and contents that characterized the teaching of World History - no longer called Universal-. In the first place, after telling our tour of research, we establish the main aspects that characterize the approached curricular designs; subsequently, in the second stage, possible lines of work are established that contribute to overcome and critically review the African History and that of the afro-descendants in that normative and in the construction of a national identity.
\end{abstract}

Keywords: History didactics, Africa, afro-descendant, decolonizing perspectives, curriculum, identity.

\section{Curriculum, identidades e outras histórias: uma mirada da história de África e os afro descendentes no contexto bonaerense}

\section{Resumo}

Neste artigo propomos refletir sob as razões pelas quais achamos que a história de África e dos afro descendentes cobra importância, especialmente no ensino da história na escola secundária Argentina. Nossa abordagem está enquadrada na análise das novas presenças e ausências destas culturas e povos nos desenhos curriculares no contexto da Província de Buenos Aires, já que nos últimos anos prestou-lhe atenção à necessidade de revisar e renovar os conteúdos da escola conformes com as demandas atuais da sociedade. Alí estas outras histórias constituíram-se como um inovador aparecimento e ruptura em relação às perspectivas e aos conteúdos euro centrados que caracterizaram o ensino da história mundial - já não mais denominada universal- Na primeira parte, depois de relatar nosso percurso de indagación, estabelecemos os principais aspectos que caracterizam aos desenhos curriculares abordados; posteriormente, na segunda parte, estabelecem-se possíveis linhas de trabalhos que contribuam a superar e revisar criticamente a História de África e dos afro descendentes nestes regulamentos e na construção identitaria nacional.

Palavras-Chave: didática da história, África, afro descendentes, perspectivas descoloniales, Curriculum, identidade. 
Si yo fuera intendente en mi primer día mandaría a ejecutar a todos los negros "motochorros» que circulan por la ciudad robando a todas las personas que se encuentran en su camino. Mandaría a trabajar a los policías que son unos inútiles inservibles y organizaría un concierto de los "wachiturros» para que todos los negros vayan y luego prendería fuego el lugar.

Agustín, intendente ficcional pro mata wachiturros ${ }^{4}$.

En marzo de 2013 en una de mis primeras clases como profesor de la materia Construcción de ciudadanía en el tercer año de la escuela secundaria decidí iniciar una secuencia de trabajo a partir de una sencilla actividad en la que interrogaba a mis estudiantes sobre sus intereses por medio de la pregunta: ¿qué harían si fuesen intendentes de la ciudad?, ¿qué propuesta tendrían? Allí apareció la voz de Agustín con la que comienza este relato. Otro niño expresó algo similar con otras palabras: «mataría a todos los negros, así no roban más y todo el mundo vive tranquilo y haría adelgazar a los policías para que puedan correr a los negros chorros y le peguen un tiro por villeros y wachiturros». Unos minutos más tarde Pedro agregó: «yo a los negros los obligaría a trabajar y el que no quiere al paredón ${ }^{5}$. Así, una y otra voz aumentaba y ampliaba dichos como los expresados — quizás creyendo que la situación era cada vez más "graciosa»- La escena de esta clase continuó con casi cuarenta estudiantes alentando al joven que había sido el más pragmático en su propuesta — «organizaría un concierto de los «wachiturros» para que todos los negros vayan y luego prendería fuego el lugar»- y que lo proclamaron como el futuro Intendente de la ciudad. Entre las ovaciones y los gritos del nombre del nuevo líder comencé a repensar la planificación anual y las carpetas del diagnóstico que debía entregar a las autoridades de la institución ${ }^{6}$.

Más allá de la enorme cantidad de aspectos que podríamos recuperar del relato de esta escena se interpuso una arista de indagación: el negro como un otro ${ }^{7}$. Pues en

4 Texto escrito por un estudiante en el contexto referenciando en este trabajo. Los nombres son ficcionales y la institución de este relato es resguardada, no obstante se tratan de expresiones textuales registradas por el autor de este trabajo. Asimismo aclaramos que algunas de las categorías nativas mencionadas tales como «motochorros» —que es una denominación de los asaltantes en motocicleta- $y$ «wachiturros» - que es una forma de llamar a las personas que viven en villas miserias a partir del nombre de una banda musical argentina, Los Wachiturros, que logró notable popularidad tanto en el país como en el extranjero- se asocian en estos discursos al ser «negro».

5 El «paredón» alude al asesinato a través del fusilamiento, una de las prácticas genocidas de la última Dictadura Militar Argentina (1976-1983).

6 Por supuesto que ese no fue el único planteo en relación a las políticas que implantarían estos jóvenes como futuros representantes del poder ejecutivo local pero sí el más llamativo y el más recurrente, sobre todo por la ingenuidad en la que esperaba que me hablasen de cuestiones como la creación de foros juveniles con la inclusión de sus voces en las políticas adultocéntricas. Otras voces más opacadas aquel día se refirieron a plantar árboles, reciclar basura, construir escuelas, etc.

7 Otras escenas también aparecieron durante esos días en las aulas: Morena, una joven que me pidió 
aquellas diferenciaciones raciales operaba una dicotomía identitaria de un nosotrosblanco frente a un otro-negro; violenta otredad que caracterizó - y aún caracterizaa la identidad nacional argentina. En la construcción del relato y experiencias de la nación los lugares de la negridad — tanto como de la indianidad - se marcan por la extranjeridad, o sea, que lo argentino no es negro y cuando hay presencia negra lo es en el pasado - que ya no lo es - o se representa como extranjera: brasileños, latinoamericanos o africanos. También es cierto que la negridad argentina está caracterizada por marcas locales —en el continuo proceso de silenciamiento y desaparición de voces, cuerpos e identidades reprimidas, acalladas y silenciadasque designan como negro a todo aquello no-europeo - blanco e occidental-: indios, afrodescendientes, «cabecitas negras» $y$ «villeros».

La voz de Agustín y sus compañeros me interpelaron y me interrogaron: pero, ¿por dónde empezar?, ¿cómo podría deconstruir sus representaciones de la otredad negra y sus prejuicios en relación al color de piel? Lo único que estaba claro es que debía «cercar» el tema y no podía sensibilizar directamente sus miradas de la cultura «villera» - $\mathrm{O}$ «wachiturra»— sin antes poder explorar la discriminación racial. Así fue como el Apartheid nos ocupó los primeros meses hasta lentamente poder abordar en nuestras clases la construcción social de las identidades negras en Argentina, revisando las imágenes, las representaciones y los procesos de blanqueamiento social de nuestras sociedades - en la línea temática de esta materia, recorriendo los derechos humanos y la participación política-. Esta incorporación no estaba aislada sino que dialogaba con el trabajo que intentaba realizar en mis clases como profesor de historia en segundo y quinto año de la escuela secundaria: en donde África y los afrodescendientes aparecían una y otra vez más entre ausencias y presencias.

Sobre ello una primera cuestión a resaltar es que la historia de África y de los afrodescendientes en Argentina durante mucho tiempo formó parte de un curriculum que podríamos denominar nulo, en términos de aquello que no se enseña y que queda invisibilizado. Que es ausente y que, retomando la lectura sugerida por Boaventura de Sousa Santos (2006), está asociado a los tipos de ausencias que no son olvidos, sino que forman parte de procesos activos de pérdidas de producción de experiencias otras ${ }^{8}$. Pues a grandes rasgos podríamos señalar que las curriculas adolecen de ideas, teorías, experiencias y procesos cognitivos y afectivos que brillan por su ausencia, empobreciendo nuestras oportunidades de colaborar en los procesos de liberación, en la construcción de la justicia social y la justicia cognitiva (Sousa Santos, 2006). Las producciones de ausencias en relación a las culturas y las historias de África en la educación argentina responden a procesos históricos complejos, los

no trabajar sobre los movimientos de la negritud porque sus compañeros la cargaban por ser «negra», y Danilo pidiéndome ayuda frente a las risas de sus compañeros que se burlaban de su color de piel y lo apodaron «Evo» como un insulto que refería al primer mandatario indígena de Bolivia.

8 El uso de la palabra otra(s) detrás del sustantivo refiere a la intención de aludir a un paradigma otro, aquel inscripto en los márgenes de la razón moderna y colonial. 
Curriculum, identidades y otras historias: una mirada de la historia de África y los afrodescendientes en el contexto bonaerense

| Francisco Ramallo |

cuales no podemos abordar aquí en su completud ${ }^{9}$. No obstante, señalaremos que en Argentina —al igual que en la mayoría de los países occidentales_ África y las enseñanzas sobre sus pueblos y culturas conforman un espacio que históricamente ha sido ignorado en la selección de los saberes del mundo escolar.

Pese a esta tendencia histórica, los cambios de la Nueva Escuela Secundaria Argentina —NESA—, iniciada en el 2006, presentan una situación que comenzó a modificar el ocultamiento del pasado africano en este país del Cono Sur. En pocas palabras, resaltamos que en Argentina la escuela secundaria viene atravesando una serie de modificaciones curriculares asociados a reformas y cambios estructurales con el fin de lograr una mayor y mejor inclusión de los jóvenes en la sociedad. En nuestro contexto más cercano, la Provincia de Buenos Aires, — dado que el sistema de enseñanza secundario se encuentra descentralizado y cada provincia elabora su propio marco normativo - en los últimos años se le prestó atención a la necesidad de revisar y renovar los contenidos escolares acorde con las demandas actuales de la sociedad, los avances en las disciplinas científicas y las realidades de los jóvenes estudiantes de la provincia como sujetos de derecho. Para el caso de la enseñanza de la Historia, la implementación de los nuevos diseños curriculares —en adelante $\mathrm{DC}^{10}$ - proponen una revisión y renovación de los paradigmas historiográficos que tradicionalmente dominaron la enseñanza de esta disciplina en la escuela, ligados al enfoque liberal positivista, para incluir a partir de primer año los enfoques más recientes y «progresistas». Asimismo, si bien es cierto que la historia de África no tiene una centralidad curricular, en el contexto de la Provincia de Buenos Aires, en los diseños curriculares para la enseñanza de la historia (2006-2010), es posible advertir una «novedosa presencia» en relación al pasado de estos pueblos ${ }^{11}$. Por ejemplo, en

9 Al respecto puede consultarse Ramallo (2015): "África en Argentina: Pedagogías descoloniales e historias otras en las aulas». Tesis de Maestría en Estudios Étnicos y Africanos. Centro de Estudios Afro-Orientales — CEAO-, Facultad de Filosofía y Ciencias Humanas, Universidade Federal da Bahía.

10 Bracchi, C. (2010) (coordinadora). Diseño Curricular para la Educación Secundaria: Marco General para el Ciclo Superior. La Plata, Dirección General de Cultura y Educación de la Provincia de Buenos Aires y Bracchi, C.; Paulozzo, M. (coordinadoras): (2006) Diseño Curricular para la Educación Secundaria 1 año: Ciencias Sociales. La Plata, Dirección General de Cultura y Educación de la Provincia de Buenos Aires; (2007) Diseño Curricular para la Educación Secundaria 2 año: Historia. La Plata, Dirección General de Cultura y Educación de la Provincia de Buenos Aires; (2008) Diseño Curricular para la Educación Secundaria 3 año: Historia. La Plata, Dirección General de Cultura y Educación de la Provincia de Buenos Aires; (2009) Diseño Curricular para la Educación Secundaria 4 año: Historia. La Plata, Dirección General de Cultura y Educación de la Provincia de Buenos Aires, (2010) Diseño Curricular para la Educación Secundaria 5 año: Historia. La Plata, Dirección General de Cultura y Educación de la Provincia de Buenos Aires y (2011) Diseño Curricular para la Educación Secundaria 6 año: Historia. La Plata, Dirección General de Cultura y Educación de la Provincia de Buenos Aires.

11 La Nueva Escuela Secundaria Argentina (2006) se organiza en seis años de escolaridad en la Provincia de Buenos Aires del primer a sexto año. El campo disciplinar de nuestro interés en esta investigación abarca las ciencias sociales en el primer año y la historia en los siguientes cinco. Aclaramos que en todas las modalidades la materia Historia aparece de segundo a quinto año; y, específicamente para el sexto año en las orientaciones de Ciencias Sociales y de Arte, se retoman los contenidos de Historia de quinto año que refieren a la Historia Reciente para ser abordados en propuestas metodológicas que 
los DC de $2^{\circ}$ y $5^{\circ}$ año de la escuela secundaria el pasado africano se vuelve clave para entender las unidades de los vínculos coloniales del triángulo comercial entre Europa, América y África y del mundo poscolonial —en el cual la descolonización de las excolonias en África y Asia traza las líneas necesarias para comprender la historia de la segunda mitad del siglo $x x-$. En este marco es evidente que aparece una historia africana, pero el mundo afrodescendiente continúa siendo silenciado y ocultado.

\section{África y los afrodescendientes: un diseño curricular}

La pregunta sobre cuál es la importancia de los contenidos vinculados a la historia del continente africano y de los afrodescendientes, según Juan Fantino (2013), se actualiza en un conjunto de aspectos interrelacionados: la vigencia, emergencia y presencia en nuestra cultura nacional, la historia común del colonialismo y el neocolonialismo entre África y América Latina y los posibles procesos de integración de los vínculos sur-sur que emergen en el nuevo milenio ${ }^{12}$. A ello también deberíamos agregar el contexto de insurgencia y resignificación identitaria que caracteriza a las sociedades latinoamericanas actuales, en donde diferentes normativas educativas — como también podría ser la Ley Federal 10.639/03 que rige en Brasil— plantean nuevas lecturas identitarias y nuevas miradas de las historias nacionales. En relación a los cambios curriculares en las políticas educativas en Argentina, Jorge Huergo y Kevin Morawicki (2010) se ocuparon de analizar la reescritura contrahegemónica de la formación de docentes que se planteó en la Provincia de Buenos Aires -a partir de los nuevos marcos curriculares desde el año 2006- y a remarcar una transformación curricular que se inscribe en las iniciativas de la restitución del Estado y la recreación de la educación escolar como una política cultural no hegemónica.

Especialmente en nuestro análisis nos ocupamos de indagar en los DC de Historia y de Ciencias Sociales de la escuela secundaria los puntos de contacto con el pasado y las culturas tanto de África como la diáspora africana en nuestro continente, en términos de remarcar las tramas de presencias y ausencias que se manifiestan en estos

conduzcan al desarrollo de proyectos de investigación. Estos nuevos diseños curriculares, elaborados a partir de la Ley de Educación Provincial № 13.688, son declarados como: comunes, prescriptivos, paradigmáticos y relacionales. Entonces se trata de diseños que tienen un carácter prescriptivo, y en cada uno de ellos se presentan un estado de arte del campo de estudios como fundamentación de la propuesta, implicancias educativas y definiciones conceptuales, expectativas de logro —objetivos de enseñanza-, organización de los contenidos, mapa de organización de los contenidos, delimitación del objeto de estudio con conceptos estructurantes, conceptos transdiciplinares y conceptos básicos de la materia, y orientaciones didácticas.

12 En el estudio de esta temática las producciones existentes son reducidas, especialmente Juan Fantino (2013) despertó un inicial interés en la presencia de África — y agregaríamos, los afrodescendientesen los DC de Ciencias Sociales e Historia para el nivel secundario bonaerense enmarcada en la discusión sobre la construcción de la identidad nacional y las nuevas situaciones producto de la globalización. En este trabajo se destacó la poca presencia de la historia de África y los afrodescendientes —al igual que las comunidades originarias - en la educación formal argentina y se refirió a la inexistencia de estos actores, a priori definidos como «otros» en la «identidad argentina». 
documentos. Las primeras son múltiples —refieren a cuestiones bien complejas y profundas que sólo nominalmente presentamos aquí-, mientras que las segundas son novedosas, necesarias y se encaminan a un cambio, o al menos una reinterpretación, de los temas y las formas de enseñar historias en las aulas de nuestras escuelas.

Entre las presencias que permiten resaltar rasgos novedosos en estos documentos, queda claro que los DC retoman una idea de América y Europa que destaca importantes rasgos antes de su «encuentro» — dando visibilidad a los pueblos indígenas y las culturas locales anteriores a la presencia blanca en estas tierras-. Al mismo tiempo sugiere una asociación entre la modernidad y la denominada colonialidad, en el sentido que presenta relaciones continuas entre las transformaciones que hicieron de Europa un espacio moderno y los vínculos con otros espacios como América o África que quedaron subordinados a una condición colonial. Es en esta ruta que se espejan y se enfrentan los cambios que la modernidad introdujo primero en Europa - como la creación de Estados-nación, la Ilamada Revolución científica, los contactos con Oriente, la construcción de mercados internos y externos-y por otro lado su impacto en el contacto con las sociedades nativas de América. Sumado a ello, para los DC de segundo año en adelante se recoge una perspectiva crítica de la construcción del mundo capitalista, que contempla aspectos anteriormente olvidados como la trata de los esclavos africanos traídos a América y las configuraciones que dieron orígenes a sociedades basadas en criterios de clasificación racial. Aquí podríamos continuar enunciado una serie de ejemplos, pero sin duda una de las principales ideas discutidas en estos DC es la de reinterpretar la centralidad de Europa en la historia del mundo. Y con ello se remarca una suerte de historia de la imposición de la cultura europea sobre el resto del planeta que posibilita otras lecturas ancladas en múltiples experiencias y diversos recorridos.

Sin embargo, pese a los notables cambios de estos DC, que permiten desde sus orientaciones fomentar prácticas de enseñanza contrahegemónicas y recuperar narrativas invisibilizadas, notamos ciertos rasgos que impiden interpretar y construir los pasados de África y de las culturas afrodescendientes desde un lugar que recupere su diversidad y complejidad. En relación a ello, proponemos una serie de puntos, que tomamos como marcas y tramas, que colaboran en descentrar los rasgos eurocéntricos de los DC. Estos rasgos no son únicos ni exhaustivos, sino que conforman una serie de aspectos que se vuelven necesarios para interpretar estas historias otras en este contexto curricular.

\section{La historia África y de los afrodescendientes como subsidiaria y residual frente a un relato aún eurocentrado}

La historia de África y de las culturas afrodescendientes que se representa en los DC parecería que no explicaran nada por sí misma, es decir, si bien se recurre a los pasados de estos pueblos —anteriormente invisibilizados - aún su recuperación por sí sola no 
es capaz de explicar la constitución del mundo moderno y colonial en América. En efecto, advertirnos la pérdida de cierto espesor propio que la mirada intraeuropea y, si se quiere, intraamericana tiene en estos documentos. Esa condición le da un carácter de historia subsidiaria o residual sin poder, a partir de la inclusión de estos pasados, comprender la historia de todos los pueblos del mundo desde un lugar pluriversal. Asimismo, esta tendencia reproducida y construida en estos documentos no impide ir a un más allá del relato eurocentrado —reconociendo que los desprendimientos que de él hacemos en nuestras sociedades occidentales siempre es parcial-, recuperando otras lógicas de interpretar los tiempos, los espacios y las relaciones entre los seres humanos. En tal sentido, África completa y acompaña un recorrido histórico con pretensión universal, en el cual Europa continúa presentándose como el centro de un mundo al cual las historias de los pueblos del Abya Yala —América-, África, Asia y otras regiones deben acoplarse. De hecho, los africanos aparecen como actores de reparto en el trasfondo de las escenas que se exponen en función de los contactos con la cultura blanca, europea y occidental. Esta arista repara además en los peligros de la occidentalización de África y de su inclusión en nuestras sociedades, denunciando el uso político y oportuno de África en el siglo xxı.

\section{Imagen negativa y prejuiciosa de la historia África y de la diáspora}

La presencia de la historia de África y de la diáspora no resuelve su compresión. Compartiendo lo señalado por Juvenal de Carvalho Conceicão (2012), estamos convencidos de que es justamente la idea que se tiene de África lo que se constituye como el principal obstáculo para enseñar sus historias pues lógicamente el desinterés aumenta si queremos conocer un lugar negativo —de muerte, hambre, miseria, violencia, corrupción, masacres, entre otras imágenes cotidianas que circulan en nuestras sociedades-. Frente a lo señalado, los DC no plantean ninguna ruptura en términos conceptuales de las imágenes y representaciones de África y los afrodescendientes, dejando de lado la necesaria desconstrucción para interpelar estos saberes. Más aún, las subjetividades diaspóricas continúan ocultadas en esa representación ajena de lo africano como personas sumamente distantes del «nosotros»; en los DC el africano se transforma en un «otro» tan distante que no llegamos a establecer una relación de proximidad afectiva, ignorando que en otros momentos de nuestra historia conformaron una parte importantísima de nuestra población y que hasta nuestros días sus identidades aparecen invisibilizadas. Así, los DC representan a África como una exterioridad, como un continente con "poca historia» —Cuando no "sin historia»—, en la que los hombres y mujeres de allí vivían y viven en un estado de barbarie y de salvajismo, incapaces de construir culturas complejas, respetables e importantes.

\section{Historia única de África e imagen homogénea}

La condición residual y subsidiaria de su historia y los prejuicios e imágenes negativas se asocian también a una representación homogénea y única de África: 
el pasado africano se identifica como uno solo — que además es eurocentrado- . Los DC reproducen y construyen silencios de sus particularidades, complejidades y diversidades. Esa imagen irracional, primitiva y deshumana, marcada por el distanciamiento y la desinformación, constituyen una historia única que no da lugar a su multiplicidad cultural. Esa homogenización del continente - que muchas veces es designado en nuestro hablar cotidiano como un país - se presenta como una totalidad única tanto en los aspectos ambientales como en los sociales y culturales. La incalculable diversidad africana es totalmente ocultada en el silencio de espacios, lenguas, valores, creencias, religiones, técnicas, experiencias que son dejadas de lado por la invención de esa África atrasada y sin cultura.

\section{África como territorio de un pasado lejano}

La presencia más fuerte de África en los DC es su asociación a las «culturas primitivas» las cuales continúan hasta el presente en esa imagen única y homogénea que se extrapola también en el orden de lo temporal. La historia de África parecería estar asociada a la historia de una temporalidad sin posibilidad de existencia coetánea; en ese proyecto liderado por Europa se conformó una historia universal que le quita la posibilidad de existencia en el tiempo presente a las formas no europeas. África, de ese modo, aún en los tiempos más recientes, es representada a partir de una imagen primitiva y cuando referimos a sus historias nos remitimos a los primeros habitantes del planeta y a «hombres-monos».

\section{Invisibilidad de los afrodescendientes y del mundo negro en nuestra sociedad más cercana}

La presencia de la historia de África y de las culturas africanas que podemos advertir constituye a su vez una gran ausencia de las culturas afrodescendientes en el contexto del Estado argentino. Esa novedosa e incipiente visibilidad es acompañada por una profunda ausencia de referencias del mundo negro en la historia nacional. Desde este DC la enseñanza de la historia de nuestra sociedad más cercana -la argentina antes que latinoamericana - ignora y desconoce el lugar de las culturas afrodescendientes en nuestro territorio durante la Colonia, la representación de los soldados negros en las guerras de Independencia, entre otros aspectos, una tendencia que aumenta en su ocultamiento con el desarrollo del Estado-nación argentino. Esta invisibilidad es clave para fundamentar la idea de que Argentina es un país «sin negros» o de baja representación de afrodescendientes, silenciamiento que colabora con la consolidación de una imagen despreciativa y de pérdida de derechos identitarios de los argentinos. 


\section{Incoherencia y desconexión en la historia de África y los afrodescendientes}

En el mismo sentido cabe remarcar una cierta incoherencia que atraviesa a estos DC pues, tal y como se entiende esa África primitiva y lejana de los diseños de primer y segundo año y luego en el quinto año, la descolonización e independencia política de los países africanos conforma un espacio revolucionario en la ordenación del nuevo mundo. Sumado a ello, las ligaciones de los afrodescendientes con África es una desconexión más en la escasez de vinculaciones que los negros representan en la historia nacional.

\section{África y los afrodescendientes: una apuesta en las aulas}

Dado lo anteriormente señalado, creemos que las ausencias, nuevas presencias, permanencias, rupturas y los territorios de desencuentros de los DC interpelan y colocan el desafío de establecer rasgos a revisitar y sobre todo posibilidades, lecturas y secuencias didácticas que posicionen a las culturas africanas y afrodescendientes en otras historias. Más allá de reconocer que no es posible estudiar la historia de América desconociendo y excluyendo la historia de África, y que la Modernidad, el capitalismo, el colonialismo, difícilmente puedan ser interpretados ignorando la marca afrodescendiente de nuestra región, lo que está claro es que la falta de informaciones o sobre todo las informaciones equivocadas sobre África y sus culturas hacen prevalecer un imaginario precario y prejuicioso sobre los orígenes africanos y las identidades diaspóricas de nuestra región.

Ahora bien, ¿cómo podríamos/deberíamos/quisiéramos que se enseñe la historia de África y los afrodescendientes en el contexto aquí presentado?, ¿qué imágenes de las culturas africanas y afrodescendientes se han de construir en las aulas?, ¿cómo impulsar prácticas de enseñanza que consideren estas otras historias y otros sujetos más allá de los cánones establecidos por las prescripciones normativas y culturales dominantes en los espacios escolares? Si bien estos interrogantes son de difícil abordaje, intentaremos establecer una propuesta, un ensayo, un recorte que podría ejemplificar un recorrido diferente y necesario con respecto a estas temáticas. En tal sentido sugerimos reelaboraciones de secuencias didácticas a partir de contenidos articuladores y presentamos una secuenciación de tres contenidos didácticos que a modo de ejemplo cobran importancia para trabajar estas historias en nuestras escuelas.

\section{La diáspora como contenido articulador de la enseñanza de segundo año}

El aporte de los pueblos africanos constituye uno de los ejes de la cuarta unidad del DC para la enseñanza de la historia en el segundo año. Si bien esta unidad se propone articular con las otras el desarrollo curricular, la diáspora como contenido se plantea 
de manera aislada y pierde su potencialidad para explicar la contribución de las culturas africanas en la construcción de las sociedades latinoamericanas. Por lo que se vuelve clave reconsiderar esta cuestión en un andar por la diáspora que colabore en la reinterpretación de las historias eurocentradas - que caracterizan tanto a ésta como a otras narrativas nacionales-. Creemos oportuno recorrer la historia de la construcción del (des)orden moderno y colonial en América a partir de un abordaje diaspórico, en el sentido que se instaure la idea de que la diáspora africana es parte de la historia de nuestro continente. Lejos de plantear el tráfico de esclavos como un tema más del DC, fundamental para explicar la colonización de determinados espacios de la región y de la construcción de la sociedad de castas que se conformó en el Río de La Plata, proponemos interpretar a los movimientos diaspóricos de las culturas negras por los diferentes territorios de América como un eje transversal y explicativo de las demás unidades. De modo tal que las diásporas de los pueblos negros puedan ser una puerta de entrada para comprender al mundo moderno y colonial en el que se inscribe la sociedad capitalista y sus diferentes alternativas.

Además, la diáspora como contenido articulador del segundo año enlaza procesos históricos e identitarios de nuestras sociedades, permitiendo explicar los tres grandes temas del DC: (1) el colonialismo, (2) la inserción en el sistema capitalista y (3) la construcción de los Estados-nación en América. Asimismo, se articula con otros dos aspectos fundamentales de la enseñanza de la historia en la escuela secundaria argentina que podrían retomarse a posteriori: el blanqueamiento social, asociado al proceso de construcción e imaginación de la nación, y el proceso de descolonización que se inició con la valorización de formas otras de existencias, diferentes a las reconocidas por los europeos como universales.

\section{El deseo de blanqueamiento social como contenido articulador del cuarto año}

La construcción del Estado-nación en Argentina, contenido que recorre el trayecto del DC para el tercer año, podría explicarse conjuntamente con el de deseo de blanqueamiento social expresado por los discursos y las prácticas de los diferentes itinerarios políticos que hegemonizaron el dominio político en estas tierras. En ese sentido es que aludimos a la idea de deseo de blanqueamiento social intentando atravesar el mito e imaginario social que silencia la presencia negra en la actual nación argentina, en cuanto este contenido se vuelve esencial para entender las características que tomó nuestra sociedad y para desocultar ese pasado negado en la identidad nacional. Los negros borrados y exterminados bajo las políticas nacionales hegemónicas del blanqueamiento, la homogenización y el genocidio, remarcan que la matanza de los indios acompañó a la invisibilización de los negros. De este modo esta consideración permite un transitar diferente que muestra desde la tensión un proyecto ideario de un país que consagró a Europa y una nación inventada en función del mito fundador del «crisol de razas» y de los «barcos». Se reconoce 
que, a diferencia de otros países de la región como Brasil, en Argentina la identidad afrodescendiente conforma una ausencia real por la desaparición y genocidio del pueblo negro y una virtual por la marginalización e invisibilidad de la diversidad étnica y racial existente en nuestras tierras. A partir de la conformación del Estadonación a fines del siglo XIX, las élites dominantes en Argentina forjaron el discurso de la blanquedad - que caló hondo en la sociedad argentina- a través de dos mecanismos: por un lado, la asignación de la categoría «negro» a un cada vez menor número de personas -invisibilizando rasgos fenotípicos y destacando los rasgos mestizos y blancos- $y$, por otro, la insistencia en denominar como «negros» o «cabecitas negras» a los ciudadanos con escasos recursos, lo cual no implica ya una dimensión racial sino socioeconómica (Frigeiro, 2000).

A su vez, esta puerta abierta hacia las murgas, las payadas, los carnavales, el candombe argentino y uruguayo, el tango rioplatense, los quilombos y la capoeira en Brasil, contribuye a considerar la cultura negra del Cono Sur como expresiones culturales que fueron producidas como formas de resistencia cultural. Las representaciones y el lugar del negro en la escena pública se entrecruzan con el Ilamado deseo del blanqueamiento social que Ilevaron adelante las élites no sólo argentinas sino también del resto de países de Latinoamérica. En nuestra región las clases dirigentes tendieron a consolidar una idea de nación a ser construida a partir de un patrón de cultura blanca, judeocristiana y eurooccidental. La persistencia de la blanquetud como patrón estético en la naturalización de la convención estética del hombre blanco, formó parte de un ideal de blanqueamiento social que llevaron adelante las elites blancas como meta y deseo. La visión explicita de la superioridad blanca se consolidó como un discurso natural e inconsciente que perdura hasta la actualidad y nos convoca a la rebeldía: a enfrentarlo, combatiendo el racismo y ultrapasando los deseos de las élites blancas.

\section{La descolonización del mundo como contenido articulador del quinto año}

La descolonización es un proceso histórico, profundizado y normalmente asociado a las experiencias de luchas de liberación nacional de diferentes regiones de África y de Asia. Su primera confrontación se desarrolló bajo el signo de la violencia —al igual que su propia cohabitación - pero el grito descolonial, que comienza con una violencia anticolonialista e implica la construcción de un mundo común, designa mucho más que ello. Alejándonos de una mirada excesivamente política de la descolonización consideramos necesario posicionarnos en una lectura más amplia y profunda de lo que llamamos «descolonización del mundo». En contraposición a la designación del proceso de luchas independentistas y asociadas a una geopolítica colonial del capitalismo y los Estados-nación, optamos por interpretar este proceso en términos simbólicos, culturales, sociales, económicos y políticos. Un transcender que designa a la visibilidad del ser, a la resignificación de identidades, relaciones y 
modos de existir que remarcan que el mundo ya no es más el mismo. En la enseñanza del quinto año de la escuela secundaria, la descolonización se vuelve un contenido clave para interpretar la historia de la segunda mitad del siglo xx.

Siguiendo el DC en la primera unidad: «La Guerra Fría, las nuevas formas de dependencia y las luchas anticoloniales el mundo de posguerra», se ofrece un marco para comprender los pasados que serán retomados en las siguientes cuatro unidades. Allí la «descolonización del mundo» como contenido articulador de la enseñanza de quinto año implica pensar y sentir cómo se conforman territorios, identidades y posicionamientos que posibilitaron otras formas de ser y de estar en el mundo. Particularmente, aquí el pasado africano se vuelve "protagonista» de las luchas anticoloniales y de la presentación de construcción de los «otros mundos posibles». Recurrentemente - y cada vez más - en las aulas de Historia se estudia la Guerra de Argelia, se referencia la obra los Condenados de la Tierra de Frantz Fanon, se alude a la construcción del pensamiento negritudinista y se contemplan las reivindicaciones de los afrodescendientes y las identidades diaspóricas. Con estos abordajes la descolonización aparece como un proceso histórico que da luz a la reivindicación política —y, más lentamente, A la económica, social, cultural y simbólica- de otras sociedades en relación al modelo europeo.

Por otra parte, la descolonización del mundo trae consigo la oportunidad de reapropiarse de la propia imagen de los pueblos colonizados en ese empezar a reescribir sus historias. De modo que desde esta consideración se pueden construir secuencias didácticas que recorran contenidos como: (a) la lucha anticolonial en África y Asia y la voz de Frantz Fanon; (b) los movimientos por los derechos de los afrodescendientes en América, tanto desde posicionamientos como los Martin Luther King en Estados Unidos como desde otras experiencias de Latinoamérica -comúnmente olvidadas-; (c) la valorización y visibilización de los pueblos indígenas del Abya Yala; y, (d) la insurgencia del sur como una propuesta histórica de ser y de estar en un mundo actual.

\section{Entonces... ¿por qué estudiar la historia de áfrica y los afrodescendientes?}

La historia de África, de los afrodescendientes y del mundo negro en el contexto aquí analizado - y posiblemente en otros supuestos o estudiados - se inscribe en esas historias que importan y que reparan la dignidad humana, pues construyen un espacio de resistencia a la narrativa eurocentrada y racializada en un rescate de la memoria colectiva y de la historia de la comunidad negra que no sólo es importante para la reivindicación y visibilidad de las culturas negras de nuestra región sino que también lo es para todos los seres humanos. Independientemente de sus ascendencias «étnicas», estas otras historias dejan atrás los prejuicios y la naturalización que 
históricamente beneficiaron al hombre blanco, occidental, cristiano y heterosexual sobre las otras existencias. En tal orientación, un punto que nos interesa resaltar es que estos DC se constituyen como una posibilidad que transciende las viejas lógicas de los Estados-nación en América Latina. En estos términos, estudiar la historia de África y los afrodescendientes, en el marco de la enseñanza eurocentrada y racializada que caracterizó el modo de comprender los pasados en nuestras escuelas, significa abrir una puerta para repensar la constitución de nuestros pueblos y las diversas subjetividades que los componen a escala nacional y a escala continental.

Leer estos DC es asimismo reflexionar sobre lo que significa ser argentino desde el orden de la memoria y en términos derechos identitarios. Sobre esta dimensión de lo curricular dejamos atrás la idea de que cuando pensamos en el curriculum referimos apenas al conocimiento e interpelamos cómo el conocimiento que constituye el curriculum está centralmente vinculado a aquello que somos y a aquello que nos tornamos. Siguiendo a Tomaz Tadeu da Silva (2014), en este contexto cabe preguntar(nos): ¿por qué construimos ese conocimiento identitario y no otro?, ¿qué intereses hacen que ese conocimiento identitario y no otro esté en ese Curriculum?, y, centralmente, ¿por qué privilegiar a un determinado tipo de identidad o subjetividad y no a otra? En consecuencia, más allá de los rasgos señalados creemos que los DC deben ser interpretados como documentos identitarios.

Frente a ello, estos DC presentan ciertos rasgos de las culturas africanas en su intención de superar la visión eurocéntrica y racializada que caracterizó las anteriores normativas educativas, no obstante los vínculos entre las culturas africanas y la identidad nacional (desde las producciones culturales hasta las diferentes presencias de afrodescendientes en nuestra región) continúan en una dimensión secreta e invisible. En el caso argentino (al intentar delimitarlo para compararlo con otros contextos, parecería que cuando se debe enseñar sobre las culturas africanas se lo hace únicamente para cuestionar la centralidad europea de la historia, en un intento de ampliar sus relatos con la variedad y multiplicidad de experiencias del mundo). De modo que las culturas africanas y afrodescendientes continúan apareciendo como un "otro", algo ajeno y desconectado de nuestra historia. Diferente es por ejemplo el caso del vecino Estado de Brasil en donde existe una justificación y fundamentación de carácter identitario al presentar estas temáticas en su Curriculum, allí África asume un significado en la conciencia del pueblo negro y la valorización de la ascendencia africana (por supuesto mayoritaria y más visible que la de nuestro país).

A partir de estos DC es posible preguntarnos: ¿cuál es la contribución —o la importancia- de estudiar a las culturas africanas y afrodescendientes en nuestro contexto? Inicialmente podemos enunciar aquí tres aspectos interrelacionados. En primer lugar, está claro que dejan atrás a la historia única y a la narrativa universal que ignora e invisibiliza a los sujetos y las experiencias no-europeas; además de recordarnos que no sólo existe una historia de dominación, sino que también 
nuestros pasados están colmados de historias de liberación y humanización, en las cuales las experiencias de los pueblos negros tienen mucho para enseñarnos. En segundo lugar, su potencialidad para comprender nuestra historia a partir de los diálogos sur-sur, de los vínculos entre territorios más allá de la cartografía colonial, interpelando las rutas África/América y América/África. Finalmente, y con mayor firmeza, estamos convencidos de que estos pasados combaten al racismo y a la racialización que caracteriza nuestros contextos educativos — tan violentamente expresados en discursos como el relatado en la escena inicial de Agustín-. El valorizar otras experiencias de la Modernidad y el escuchar historias silenciadas que abonan a las memorias y las identidades marginalizadas ofrecen rupturas a discursos y prácticas racistas.

Sobre este último aspecto creemos que la educación es capaz de ofrecer un camino para enfrentar el racismo, camino que no es único pero que es necesario en la tarea de transformación de nuestras mentes colonizadas (Munanga, 2008). En este horizonte reconocemos que si existió una educación racista también puede existir una antirracista, por ello es que insistimos en lo sugerente que es estudiar estos pasados como freno ante la ignorancia y el desconocimiento que enmarcan las prácticas de discriminación y de racismo al mundo negro en nuestras sociedades. Más que el rechazo al color de la piel, el racismo se constituye en la negación de historias, en el ocultamiento de la diversidad y del reconocimiento de la riqueza de las experiencias humanas. Más aún, conocer estas historias permite una afirmación positiva de identidades constitutivas de nuestros pueblos en la medida que los saberes sobre África contribuyen al desvelamiento y la resignificación del ideario prejuicioso, simplista y cargado de estereotipos que nutren el imaginario social sobre las identidades negras. Esto promueve el fomento activo de la igualdad de oportunidades para todos, creando medios para que las personas pertenecientes a grupos socialmente discriminados puedan vivir con las mismas condiciones de existencia.

En el contexto bonaerense de la enseñanza de la historia desde lo curricular queda claro que la tendencia a una historia que marque una ruptura con el eurocentrismo dominante creó una lectura de África como un «otro»—sin que se destaque a los afrodescendientes de este país y manteniéndolos aún en un lugar de invisibilidad-. Sin embargo, después de tanto tiempo de un curriculum con contenidos eurocéntricos y racializados, estas normativas denuncian fracturas a la Modernidad dominante y fugas identitarias. La ambigüedad que pueden expresar estos documentos se explican en la desarticulación de un imaginario social ya constituido, de modo que nos enfrentamos a una propuesta de desconstrucción y reconstrucción constante, cotidiana y siempre parcial. En ese camino aún nos queda mucho por andar y las aulas son un buen espacio para comenzar. 


\section{Referencias}

Carvalho, J. (2012). A ideia de África: obstáculo para o ensino de história africana no Brasil. Projeto Historia, 343-353.

Da Silva, T. (2014). Documentos da identidade: uma introdução às teorias do curriculo. Belo Horizonte: Autentica Editora.

De Souza Santos, B. (2006). La sociología de las ausencias y la Sociología de las Emergencias: para una ecología de saberes. Renovar la teoría crítica y reinventar la emancipación social. Buenos Aires: CLACSO.

Fantino, J. (2013). La presencia de África en los Diseños Curriculares de Ciencias Sociales e Historia para el nivel secundario bonaerense. Revista Clio y Asociados, 17 .

Fernández, I. (2014). Miradas Descoloniales en la Educación. Revista Intersticios: Filosofía Latinoamericana, Filosofía Política, Historiografía, 3.

Frigeiro, A. (2000). Cultura negra en el Cono Sur: Representaciones en conflicto. Buenos Aires: EDUCA.

Huergo, J., y Morawicki, K. (2010). Una reescritura contrahegemónica de la formación de docentes. Revista Nómadas, 33, 129-145

Munanga, K. (2008). Superando o racismo na escola. Brasília: Ministério da Educação.

Ramallo, F. (2015). África en Argentina: Pedagogías descoloniales e historias otras en las aulas (tesis de maestría). Universidad Federal da Bahía.

Recibido: 24 febrero de 2016

Aceptado: 9 mayo de 2016

Cómo citar: Ramallo, F. (2016). Curriculum, identidades y otras

historias: una mirada de la historia de África y los afrodescendientes

en el contexto bonaerense. Praxis Pedagógica, 19, 13-28 